\title{
Parametric design and mechanical performance analysis of hyperbolic flat reticulated shells
}

\author{
Xiaoyang $\mathrm{LU}^{1, \mathrm{a}}$ Tao $\mathrm{LI}^{1, \mathrm{a}}$ Shaobo $\mathrm{LU}^{2, \mathrm{~b}}$ Haoxin $\mathrm{FU}^{3, \mathrm{c}}$ Xiong JIANG ${ }^{3, \mathrm{c}}$ Lulu \\ WANG $^{1, a}$
}

${ }^{1}$ Research Institute of Engineering Mechanics, Shandong Jianzhu University, Jinan250101,China;

${ }^{2}$ Shandong Tongyuan Design Group CO.LTD ,Jinan250101, China;

${ }^{3}$ Research Institute of Engineering Mechanics,Shandong Jianzhu Universityl,Jinan250101,China áluxy5504@163.com, ${ }^{b}$ 946761893@qq.com, ${ }^{c}$ 821985898@qq.com

Keywords: Hyperbolic flat reticulated shell, parametric design, Mechanical performance analysis, the ratio of vector high to span, number of grids.

Abstract. A parametric design macro program of five kinds of hyperbolic flat lattice shells was developed by using APDL (Ansys Parametric Design Language) parametric design language. On this basis, hundreds kinds of working conditions of three kinds of hyperbolic flat lattice shells were selected for the change of long and short span of vector high, and did the structural force performance comparison analysis. In these three types of hyperbolic flat latticed shells, the three-dimensional lattice-type reticulated shell has the most reasonable mechanical properties, with long span of the ratio of vector high to span $\mathrm{fa} / \mathrm{a}=1 / 3$ and short span of the ratio of vector high to $\mathrm{span} f \mathrm{~b} / \mathrm{b}=1 / 6$ are suitable. those provides a reference for practical engineering design.

\section{Introduction}

Four-point support double-curved flat reticulated shell structure is broad, beautiful appearance, and it occupies a certain position in large span buildings ${ }^{[1]}$. The reticulated reticulated shells ${ }^{[2]}$ can be divided into three types: monoclinic type, fuber type, three-way lattice type .This type of reticulated shell is mostly used for roofing. By analyzing the mechanical properties of such reticulated shells, it is possible to provide important materials for engineering examples.In this paper, the mechanical properties of five types of biconitic flat shells are discussed by using a long span $a=60 \mathrm{~m}$ and a short span $b=40 \mathrm{~m}$ model.

\section{Macroscopic Geometric Parameters and Geometric Description of Hyperbolic Flat}

The main parameters of the biconitic flat reticulated shell are: the length of the reticulated shells, the long side $a$, the short side $b$, the long side vector high fa, the short side vector height $\mathrm{fb}$ and the midplane high $\mathrm{f}$, the long span direction grid $\mathrm{m}$, the short span direction grid $\mathrm{n}$ (Figure 1).

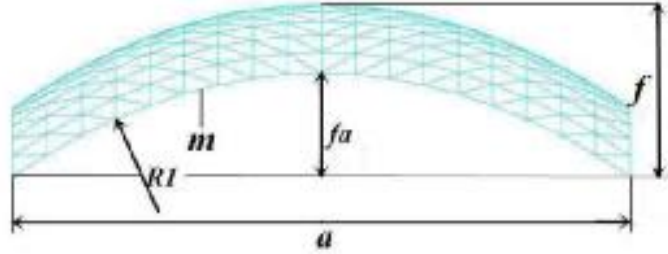

(a) Structure front view $\left(a=60, f_{a}=10\right.$, $f=16.7, m=18$ )

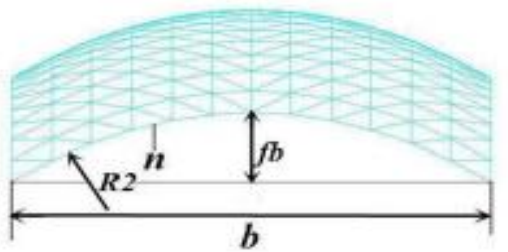

(b) Structural side view $\left(b=40, f_{b}=6.7\right.$, $n=12$ )

figure 1 The macroscopic geometric dimensions of the structure of hyperbolic flat reticulated shell 


\section{Parametric Design of Single Slanting Type Hyperbolic Flat}

In the Cartesian coordinate system, given $a, b, f, f_{a}, f_{b}, m, n$, when $f=f_{a}+f_{b}{ }^{[6]}$, the hyperbolic flat shell surface equation is:

$$
z=f-\left[f_{a}\left(\frac{2 x}{a}\right)^{2}+f_{b}\left(\frac{2 y}{b}\right)^{2}\right]
$$

(1)Calculate node coordinates, define node number:

The node number is: $(i-1) \times(n+1)+j,(1 \leq i \leq m+1 、 1 \leq j \leq n+1)$; The node coordinates are: $x=(i-1) \times a / m$, $y=(j-1) \times b / n, \quad z=f-\left[4 f_{a} / a^{2} \times((x-m / 2) \times a / m)^{2}+4 f_{b} / b^{2} \times((y-n / 2) \times b / n)^{2}\right],(1 \leq i \leq m+1 、 1 \leq j \leq n+1)$.

(2)Bar connection: the structure is divided into six parts of the bar connection, respectively, long span direction, short span direction, four obliques。

The connection number, $(i-1) \times(n+1)+j$ and $i \times(n+1)+j(1 \leq i \leq m+1 、 1 \leq j \leq n+1)$, the node is a long span bar; The connection number, $(i-1) \times(n+1)+j$ and $(i-1) \times(n+1)+j+1 \quad(1 \leq i \leq m+1,1 \leq j \leq n+1)$ the node is a short span bar; The connection number, $(i-1) \times(n+1)+j$ and $(i-1) \times(n+1)+j+n \quad(1 \leq i \leq m+1$ 、 $1 \leq j \leq n+1)$, the node is the upper left corner of the oblique bar; The connection number , $(i-1) \times(n+1)+j$ 和 $(i-1) \times(n+1)+j+n+2 \quad(1 \leq i \leq m+1 、 1 \leq j \leq n+1)$, the node is the lower left corner of the oblique bar; The connection number, $(i-1) \times(n+1)+j$ and $i \times(n+1)+j+1 \quad(1 \leq i \leq m+1 、 1 \leq j \leq n+1)$, the node is the right upper corner oblique bar; The connection number, $(i-1) \times(n+1)+j$ and $(i-1) \times(n+1)+j+n \quad(1 \leq i \leq m+1$ 、 $1 \leq j \leq n+1)$, the node is the right lower corner oblique bar.

\section{Apply loads and constraints}

The beam- 4 element (subjected to axial tension and compression, torsion and bending load) in the Ansys software was used as the structural member, and the ideal elastic-plastic material model was used, not considerring material hardening o The material density $\Phi 273 \times 6.5$, material density $\rho=$ $7850 \mathrm{~kg} / \mathrm{m}^{3}$, allowable strength $[\sigma]=215 \mathrm{MPa}$, elastic modulus $\mathrm{E}=2.06 \times 10^{11} \mathrm{~N} / \mathrm{m}^{2}$, Poisson's ratio $\varepsilon=0.3$. Considering the weight of the structural bar and the node, the equivalent load of the roof $2.35 \mathrm{kN} / \mathrm{m}^{2}$, is applied to all nodes of the reticulated shell.All the rods in the reel are taken with the joints, and the four supporting points are hinged.

\section{Analysis of Mechanical Performance of Five Kinds of Hyperbolic Flat Shell Structures}

According to the technical structure of space grid structure 3.5.1 [7], the maximum deflection value of single-layer reticulated shell should not exceed 1/400 of the shortest span, and the allowable stress is the design value of steel $215 \mathrm{Mpa}$.Figure 2 shows the stress cloud and the displacement cloud after the load, the analysis data in Table 1 of the structure of the five biconitic flat shells under the conditions of $a=60 m, b=40 m, f_{a}=10 m, f_{b}=6.7 m, f=f_{a}+f_{b}=16.7 m, m=30, n=20$. 


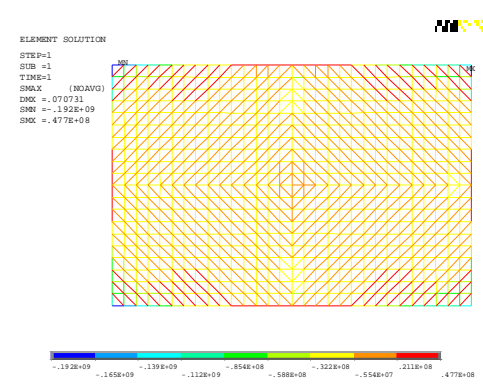

(a) Single diagonal bar stress cloud

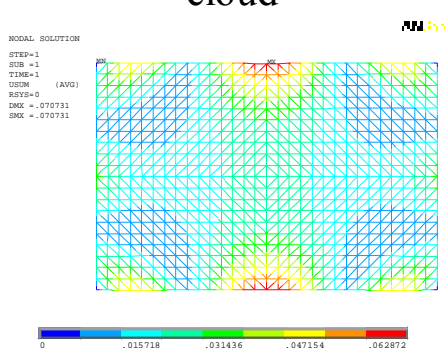

(d) Single diagonal bar Displacement cloud

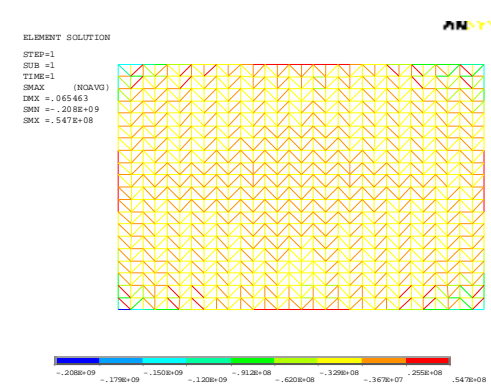

(b) Fubler stress cloud

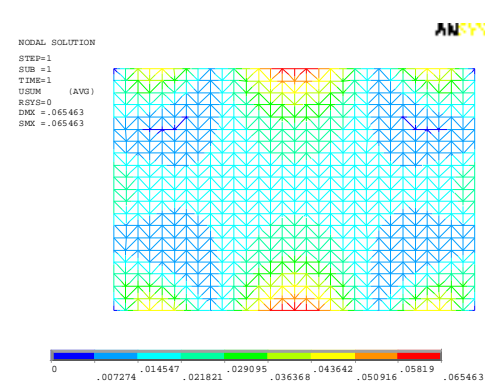

(e) Fubler Displacement cloud

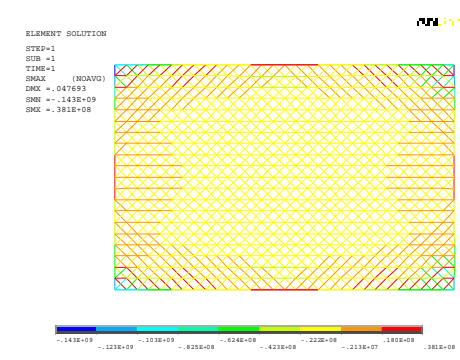

(c) Three - dimensional lattice - type stress cloud

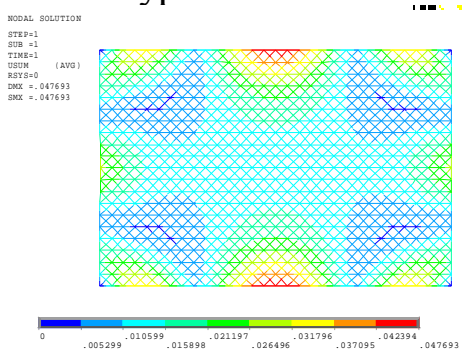

(f) Three - dimensional lattice - shaped displacement cloud

Fig. 2 Stress cloud and displacement cloud diagram of three kinds of single-layer hyperbolic flat reticulated shells ( $a=60 \mathrm{~m}, b=40 \mathrm{~m}, f_{a}=10 \mathrm{~m}, f_{b}=6.7 \mathrm{~m}, f=f_{a}+f_{b}=16.7 \mathrm{~m}, m=30, n=20$ )

Table 1 Comparison of Maximum Displacement and Maximum Stress Impact of three Hyperbolic Flat Shell Types

\begin{tabular}{|c|c|c|c|c|c|c|c|c|c|}
\hline $\begin{array}{l}\text { structure } \\
\text { type }\end{array}$ & $\begin{array}{l}\text { Long } \\
\text { span } \\
\text { (m) }\end{array}$ & $\begin{array}{l}\text { Short } \\
\text { span } \\
\text { (m) }\end{array}$ & $\begin{array}{l}\text { Long } \\
\text { span } \\
\text { vector } \\
\text { (m) }\end{array}$ & $\begin{array}{l}\text { Short } \\
\text { span } \\
\text { vector } \\
(\mathrm{m})\end{array}$ & $\begin{array}{l}\text { Long } \\
\text { span } \\
\text { grid } \\
\text { number }\end{array}$ & $\begin{array}{l}\text { Short } \\
\text { span } \\
\text { grid } \\
\text { number }\end{array}$ & $\begin{array}{c}\text { The maximum } \\
\text { displacement } \\
\text { of the } \\
\text { structure (m) }\end{array}$ & \multicolumn{2}{|c|}{$\begin{array}{c}\text { Structure } \\
\text { Maximum } \\
\text { stress }( \pm \\
\text { Mpa) }\end{array}$} \\
\hline $\begin{array}{c}\text { Single } \\
\text { diagonal } \\
\text { type }\end{array}$ & \multirow{3}{*}{60} & \multirow{3}{*}{40} & \multirow{3}{*}{15} & \multirow{3}{*}{10} & \multirow{3}{*}{18} & \multirow{3}{*}{12} & 0.071 & 47 & -192 \\
\hline Fubel type & & & & & & & 0.065 & 55 & -208 \\
\hline $\begin{array}{c}\text { Three-wa } \\
\text { y lattice } \\
\text { type }\end{array}$ & & & & & & & 0.048 & 38 & -143 \\
\hline
\end{tabular}

It can be seen from Fig. 2 and Table 1 that under the action of uniform load of $2.35 \mathrm{kN} / \mathrm{m} 2$, considering the structural weight (bar and node):

The maximum displacement of the five kinds of single-layer hyperbolic flat reticulated shells satisfies the structural stiffness requirements (the maximum displacement is less than $100 \mathrm{~mm}$ ). The maximum displacement is in the middle of the long span. The maximum displacement of the three- But are less than the allowable displacement of the structure. The minimum displacement of the structure is symmetrically distributed in the four blue regions of the displacement cloud. 
The mechanical properties of three types of single - layer hyperbolic flat reticulated shells were investigated by taking fa $/ \mathrm{a}=1 / 3 \sim 1 / 6$ and $\mathrm{fb} / \mathrm{b}=1 / 3 \sim 1 / 6,60 \mathrm{~m}, \mathrm{~b}=40 \mathrm{~m}, \mathrm{~m}=18, \mathrm{n}=12$, the analysis data in Table 2.

Table 2 Comparison of the relationship between the maximum displacement of the structure and the maximum stress

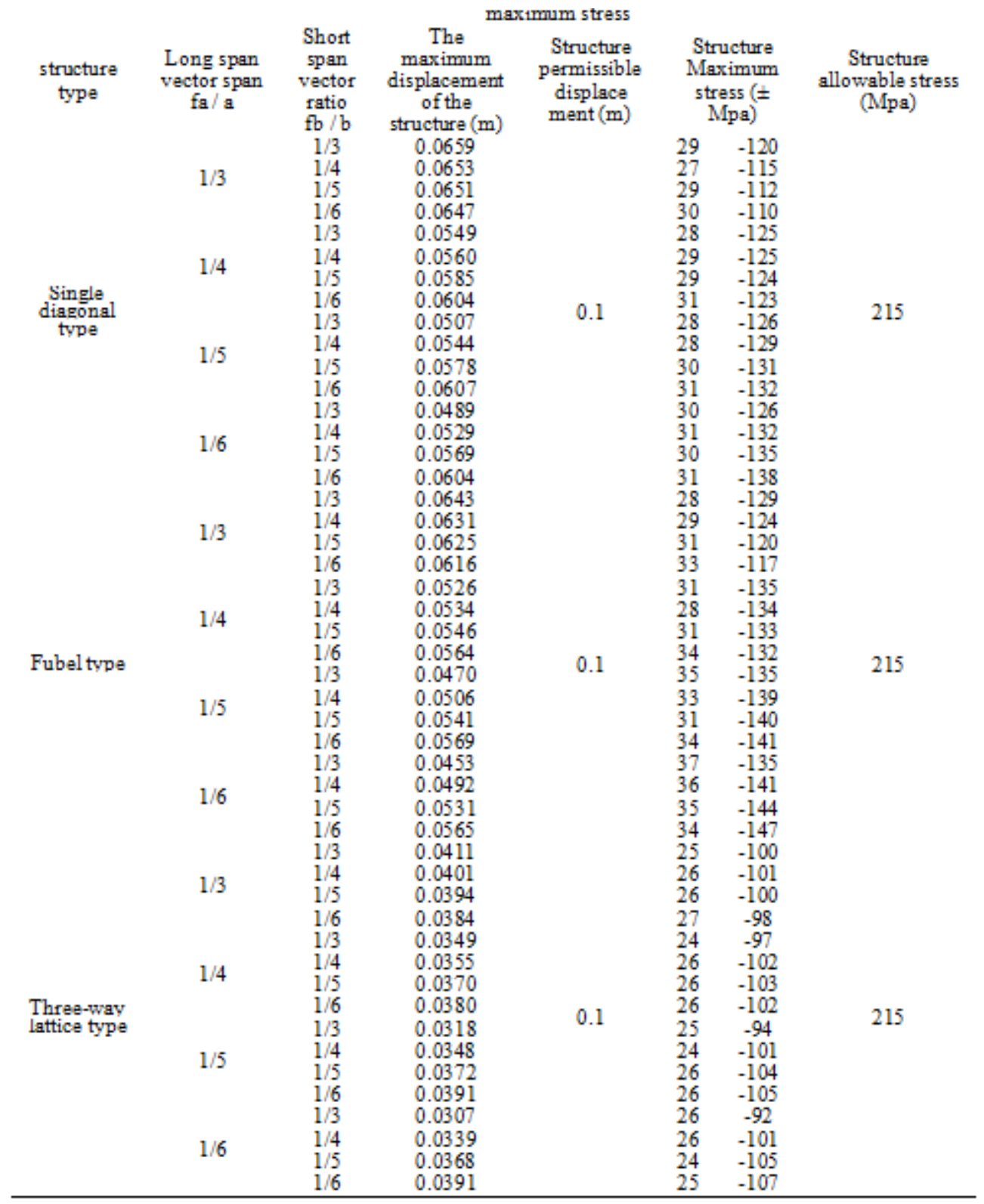

We can see from Table 2 :

The maximum displacement or the maximum stress of the structure increases with the increase of $t$ he short span vector, and as the long span vector is larger, the maximum displacement or the maximu $\mathrm{m}$ stress increases with the increase of the length of the span. The maximum displacement or the maxi mum stress of the structure increases and then decreases with the increase of the short span vector.W hen the short span vector is large, the maximum displacement or maximum stress increases with the $\mathrm{i}$ ncrease of the long span vector. With the decrease of the short span vector, the maximum displaceme $\mathrm{nt}$ or the maximum stress increases with the increase of the long span vector Reduced. The minimum value of the maximum displacement or maximum stress of the structure appears at the ratio of $\mathrm{f}_{\mathrm{a}} / \mathrm{a}=$ $1 / 6, f_{b} / b=1 / 3$ or $f_{a} / a=1 / 3, f_{b} / b=1 / 3$. 


\section{Conclusions}

In this paper, the changing behavior of the single-layer hyperbolic flat shell structure under 130 working conditions is discussed, and the following conclusions are drawn:

In the three types of single-layer hyperbolic flat reticulated shell structure, the three-way grid type of the most reasonable performance, in the actual engineering design, can be preferred; The change of long and short span vectors has a certain influence on the maximum displacement and maximum stress of three types of single-layer hyperbolic flat shells; The mechanical properties of the three kinds of single-layer hyperbolic flat reticulated shells meet the structural strength stiffness requirements under the optimal vector span ratio and the optimal grid number.

Single-layer hyperbolic flat shell to meet the requirements of the performance requirements under the premise of the bar should be optimized to cross-sectional size, so as to achieve the purpose of the lowest consumption of steel.

\section{Acknowledgements}

This work was financially supported by projects of Shandong postgraduate innovation (SDYY08038) and postgraduate high quality courses of Shandong Jianzhu University (YZKC201605).

\section{References}

[1] Zongyong Wen, Ming Dong, Bo Gong, Yiman Zhen,Shaohua Zhang.Study on the Change History of the Station - Record of Beijing Railway Station [J]. Beijing Planning and Construction, 2012,01: 165-172.

[2]Xiaoyang Lu, Xiaowei Zhao, Shiying Chen. Discrete variable reticulated shell structure optimization design [M], Beijing: China Construction Industry Press, 2013.

[3] GB50009-2012. Structural load specification [S]. Beijing: China Construction Industry Press, 2012.

[4] Yi Wu, Shizhao SHEN, Xin CHEN .Stability of single-layer hyperbolic flat reticulated shells [J]. Journal of Harbin University of Architecture, 1999,04: 24-28.

[5] SHEN Shizhao.Stability of reticulated shell structure [J]. Civil Engineering Journal, 1999,06: $11-19+25$.

[6] XIAO Jianchun, CAO Xinming, MA Xing, NIE Jianguo, MA Kejian.Performance Analysis and Approximate Optimization of Prestressed Local Single and Double Layered Flat Shells [J]. Journal of Building Structures, 2006,01: 117-123. 